\title{
Breves consideraciones sobre el código aduanero del MERCOSUR (CAM). Fuentes y antecedentes de creación
}

\author{
Jonnathan Augusto Pinho De Oliveira ${ }^{1}$ \\ María Fátima Pinho De Oliveira ${ }^{2}$
}

\section{Resumen}

Esta investigación se ha desarrollado con base a los antecedentes y teorías de carácter documental, referente a análisis teórico-legal. La integración entre naciones ha tenido por norte el apoyo económico para intercambio de mercancías, para favorecer dicho comercio se han creado bloques económicos, como en el caso del MERCOSUR, así dentro de dicho proceso de integración se discuten normas, como el caso que ocupan estas líneas sobre el Código Aduanero del MERCOSUR (CAM). El Código Aduanero del MERCOSUR (CAM) aprobado en agosto 2010 mediante la Decisión del Consejo de Mercado Común (DEC-CMC) 27/10, establece la obligatoriedad de su incorporación al ordenamiento jurídico de los Estados miembros. La adopción y puesta en vigencia del CAM no es materia que deba tomarse simplemente, toda vez que estarán en juego normas reglamentarias y complementarias a ser dictadas por el CMC, el Grupo Mercado Común (GMC) y posiblemente la CCM, así como el hecho cierto que las disposiciones de la legislación aduanera nacional que colidan con las normas del MERCOSUR, deben ser desaplicadas.

Palabras Clave: Código Aduanero; MERCOSUR; intercambio de mercancías.

\section{Abstract}

Integration between nations has had, as a goal, the economic support to exchange goods. In order to favor such trade, economic blocs have been created, as is the case of MERCOSUR, so within that integration process, rules are discussed, such as the case that these Lines on the MERCOSUR Customs Code (CAM). The MERCOSUR Customs Code (CAM) approved in August 2010 by the Decision of the Common Market Council (DEC-CMC) 27/10, establishes the obligation to incorporate them into the legal system of the States Parties. The present investigation has been developed based on the antecedents and theories of documentary character, referring to theoretical-legal analysis. The adoption and entry into force of the CAM is not a matter that should be taken simply, since there will be regulatory and complementary rules to be issued

1 Licenciado en Derecho. Profesor adscrito al Departamento de Tecnología de Servicios de la Universidad Simón Bolívar. Correo: jpinho@usb.ve

2 Máster en Derecho. Profesora adscrita al Departamento de Tecnología de Servicios de la Universidad Simón Bolívar. Correo: mpinho@usb.ve

Recibido: 25/04/2017 Aprobado: 16/08/2017

Pinho-De Oliveira, J., \& Pinho, M., F. (2017). Breves consideraciones sobre el código aduanero del MERCOSUR (CAM): fuentes y antecedentes de creación. Ciencia e Interculturalidad, 20(1), 32-41. 
by the CMC, the Common Market Group (GMC) and possibly the CCM, as well as the fact That the provisions of national customs legislation that are in conflict with MERCOSUR standards must be disregarded.

Keywords: Customs Code; MERCOSUR; Exchange of goods.

\section{Introducción}

Dentro de los procesos de integración de las aduanas, es decir, la Administración Aduanera en sentido amplio, cabe destacar que las mismas juegan un papel importante, pues son los órganos que van a ejecutar en la práctica dicho proceso de integración, donde llevan a cabo lo dispuesto en los Tratados o Convenios Internacionales, es decir, normas de Derecho Internacional, y por ello requieren normas claras referentes a la materia que, además, sean de aplicación uniforme en los Estados miembros, para que así no se presenten lagunas o dudas y se pueda garantizar una correcta aplicación e instrumentación del Arancel Externo Común.

El MERCOSUR se percató de ello y en 1994, a través de la Resolución del Grupo Mercado Común $\mathrm{N}^{\circ}$ 13, ordenó la realización de un "Código Aduanero MERCOSUR" y de sus normas de aplicación. El 16 de diciembre de 1994, en la ciudad brasileña de Ouro Preto, (Oro Negro), se firmó la Decisión CMC N²5/94, mediante la cual se aprobó un proyecto de Código Aduanero MERCOSUR, para cuya entrada en vigencia era necesaria la aprobación legislativa de por lo menos dos de los cuatro. Estados integrantes del MERCOSUR. Sin embargo, y pese a ser un anhelo común y compartido, sólo lo aprobó la República del Paraguay, se argumentó que había sido un código creado muy apresuradamente, que no regulaba aspectos esenciales y de vital importancia para las partes.

Tras las consideraciones anteriores se conformó un Comité Técnico N. ${ }^{\circ}$ 2, "Asuntos Aduaneros" a los fines de que elaborase un "Protocolo Adicional del Código Aduanero MERCOSUR"; dicha tarea se llevó a cabo entre 1997 y marzo de 2000, el Anteproyecto así obtenido (ACAM) no alcanzó el consenso técnico, ni político necesario respecto de un conjunto de temas de variado grado de complejidad. Por lo tanto, tampoco fue aprobado por tratar y regular este Protocolo Adicional, materias álgidas y fundamentalmente de trato diferente en los países miembros.

El 15 de diciembre de 2003, al momento de darse nuevo impulso al MERCOSUR, el Consejo del Mercado Común, mediante Decisión $\mathrm{N}^{\circ} 26 / 03$, estableció un cronograma de trabajo para el período 2004/2006, encomendando a un Grupo de Trabajo la identificación de los aspectos conceptuales básicos del Código Aduanero del MERCOSUR que requerían definiciones por parte del GMC. 


\section{CIENCIAS SOCIALES}

Identificados esos conceptos, con fecha 20-07-2006, durante la Presidencia Pro Témpore de Argentina, en la Ciudad de Córdoba, República Argentina, se firmó la Resolución GMC No 40/06 que estableció los lineamientos y definiciones que este Grupo Ad Hoc, ha tenido en consideración para la redacción del proyecto encomendado. Esos lineamientos y definiciones, contenidos en el Anexo de dicha norma, se refieren, por una parte, a los temas cuya armonización se consideraba factible:

...contar con un Código "marco" que regule también la circulación de la mercadería intrazona durante el proceso de transición hasta la conformación definitiva de la Unión Aduanera; el ámbito de aplicación y territorio aduanero; un régimen de salida de la mercadería; la regulación específica del despachante de aduanas; la responsabilidad de los operadores del comercio exterior; el hecho generador de la obligación tributaria y el depósito aduanero...

Por otra parte, a aquéllos que, habida cuenta de las asimetrías detectadas en las legislaciones nacionales de los socios del bloque, se decidió, en una primera etapa, no regular en el Código Aduanero MERCOSUR. En esta categoría se encuentran la prescripción de la acción para exigir el pago de los tributos aduaneros, las sanciones pecuniarias, el mar territorial, entre otras.

En dicha PPT, además, se aprobó la Decisión $\mathrm{CMC} \mathrm{N}^{\circ}$ 25/o6, que creó un Grupo Ad-hoc (GAHCAM) dependiente del GMC, conformado por funcionarios especialistas en materia aduanera y derecho tributario, para la redacción del proyecto del CAM, en base a los lineamientos especificados en la referida Resolución GMC No 40/o6. Conformado el grupo y reunidos en Brasilia se comenzaron los trabajos de redacción en noviembre de 2006 , realizando luego otras veintiún reuniones mensuales, consecutivas, de una semana de duración, en cada país que ejercía la PPT del MERCOSUR.

En el transcurso de las negociaciones del GAHCAM se detectaron numerosas diferencias sustanciales en los ordenamientos jurídicos de cada Estado Parte, lo cual tornó necesario, en algunos casos, dejar de lado las normas propias u optar por no incluir en el Proyecto determinados institutos contemplados en alguna legislación nacional, los que seguirán aplicándose en virtud del principio de supletoriedad previsto en el artículo $1^{\circ}$, apartado 4 de aquél (v.g. declaración supeditada). Una tercera solución fue remitir la regulación de ciertos aspectos que en esta etapa no se pudieron concordar a las normas reglamentarias.

De hecho en las jornadas "El código aduanero del MERCOSUR desde la óptica de sus redactores" llevadas a cabo en la Administración Federal de Ingresos Públicos en Argentina, el grupo de corredactores reunidos concluyeron que los representantes del Grupo de redacción por la República Bolivariana de Venezuela se explayaron sobre la situación de Venezuela en el MERCOSUR, destacaron el histórico compromiso que 
representa el ingreso de Venezuela en el MERCOSUR, señalando que se encuentran aguardando la aprobación de Paraguay para consolidar su ingreso al MERCOSUR. Indicaron que el SENIAT participó en 19 de las 22 reuniones del Grupo Ad-hoc para la redacción del Código Aduanero del Mercosur (GAHCAM) para tratar quizás uno de los temas de trascendental importancia de Venezuela en los últimos años en ese esquema de integración. Siendo la piedra angular de una nueva arquitectura regulatoria. El CAM logra establecer reglas que apoyan el funcionamiento correcto y armónico del sistema aduanero, contribuyendo a la reducción de los costos que soportan las empresas que dependen directa o indirectamente del comercio internacional.

En agosto de 2008, llegado a un importante grado de avance en la redacción del proyecto, las autoridades aduaneras de Venezuela lo sometieron a consulta de todos los operadores y profesionales que están representados en el Consejo Consultivo Aduanero, otorgándoles un plazo para que realizaran las observaciones pertinentes. Surgieron así setenta y dos recomendaciones, tanto parciales como totales, de distintos artículos e institutos, de las cuales cincuenta y siete fueron recogidas, previo estudio interno y discusión en la mesa de negociación internacional.

\section{Materiales y métodos}

Esta investigación es de carácter cualitativa desde una perspectiva hermenéutica porque tuvo como objetivo realizar un análisis teórico-legal de los antecedentes de la creación y discusión del Código Aduanero del MERCOSUR. Para la elaboración del Código Aduanero del MERCOSUR se tomaron en consideración los siguientes antecedentes:

\section{- Antecedentes Nacionales:}

1. Código Aduanero Argentino (Ley No. 22.415).

2. Código Aduanero Paraguayo (Ley No. 2422/04 y su Reglamento Decreto No. 4672/05).

3. Código Aduanero Uruguayo (Decreto Ley No. 15.691/84).

4. Reglamento Aduanero Brasileño (Decreto No. 4543/2002) y (Decreto No. 6.759/og).

\section{- Antecedentes Regionales (MERCOSUR)}

1. Código Aduanero del MERCOSUR (Decisión CMC 25/94).

2. Código Aduanero del MERCOSUR (versión marzo año 2000).

3. Normas de Aplicación del Código Aduanero MERCOSUR (NACAM).

4. Decisiones del Consejo del Mercado Común (en particular, la Dec. CMC Nro. 50/04).

5. Resoluciones del Grupo Mercado Común. 


\section{CIENCIAS SOCIALES}

\section{- Antecedentes Internacionales}

1. Convenio Internacional para la Simplificación y Armonización de los Regímenes Aduaneros. Convenio de Kyoto Revisado.

2. Código Aduanero Europeo (Reglamento CEE No. 2913/92), y el Código Aduanero Europeo denominado "Modernizado" (Reglamento CE No 450/2008).

3. Código Aduanero Centroamericano (CAUCA III - Año 2002)

4. Borrador del Código Aduanero Comunitario Andino (Versión 2007).

5. Acuerdo General sobre Aranceles Aduaneros y Comercio (GATT)

\section{Resultados y discusión}

El CAM fue aprobado mediante la decisión del Consejo del Mercado Común (CMC) núm. 27 de 2010, comprometiendo a los Estados a realizar las consultas y gestiones necesarias para la eficaz implementación del mismo dentro de sus respectivos sistemas jurídicos, en los próximos seis meses, su Artículo 3 establece la obligatoriedad de su incorporación al ordenamiento jurídico de los Estados Partes.

De acuerdo a la información oficial que se encuentra en el portal web del MERCOSUR, la internalización de la DEC-CMC 27/10 y del CAM anexo a ésta, solo habría sido efectuada por Argentina mediante Ley 26.795 publicada en fecha 13/12/2012 en su Boletín Oficial. El Artículo $2^{\circ}$ de dicha Ley establece que el CAM entrará en vigencia una vez que haya sido internalizado por todos los Estados Partes, de conformidad con lo dispuesto en el Articulo 40 del Protocolo de Ouro Preto sobre la estructura institucional del Mercosur.

La relevancia del CAM se encuentra indicada en sus considerandos ut supra, se destaca que los Estados Partes deberán aprobar el Código Aduanero del MERCOSUR con el objeto de permitir la implementación de la libre circulación de mercaderías importadas de terceros países al interior del MERCOSUR. Se recomienda entonces que la adopción de una legislación aduanera común, sumada a la definición y actualización de los institutos que regulan la materia aduanera en el ámbito del MERCOSUR, creará condiciones favorables para fortalecer en la profundización del proceso de integración.

Es preciso recordar que los antecedentes regionales de este CAM se remontan al Tratado de Asunción (1991), donde se estableció el compromiso de armonizar las legislaciones en las áreas pertinentes, para fortalecer el proceso de integración (Artículo 1). En virtud de lo anterior, mediante la DEC CMC 01/92 se creó un cronograma de adopción de medidas para el logro de los objetivos de la integración, entre otras acciones, la proyección de una legislación aduanera básica MERCOSUR, para la armonización de la legislación. 
De acuerdo a las consideraciones anteriores se diseñó y aprobó, mediante DECCMC 25/94, el primer CAM del MERCOSUR, integrado por 186 artículos, pero lamentablemente no llegó a entrar en vigor debido a la falta de internalización en los Estados Partes. Aun cuando su penúltimo articulo establecía que entraría en vigencia a los 30 días del depósito del segundo instrumento de ratificación, es decir, que solo se requería dicha acción por dos (2) de los Estados Partes, Paraguay fue el único país que lo incorporó, transitoriamente, a su ordenamiento jurídico. (Ríos, 2013).

Luego de ello, se dispuso años más tarde, mediante DEC-CMC 26/o3, aprobar un programa de trabajo que comprendía identificar aspectos conceptuales básicos y definiciones para la revisión del CAM. A través de la DEC-CMC 54/o4, se acordaron normas para la eliminación del doble cobro del Arancel Externo Común, y un plazo para la puesta en vigencia del CAM. A estos fines mediante la DEC-CMC 25/o6, se encargó a un Grupo Ad Hoc redactar y elevar al Grupo Mercado Común (GMC), el proyecto de CAM, órgano que mediante Resolución 40/06 estableció definiciones y lineamientos a tener en cuenta para la redacción del CAM. (Ríos, 2013).

Mediante el DEC-CMC 27/10 finalmente se aprobó el CAM, el cual deberá ser internalizado por cada Estado Parte, incluida Venezuela, para que entre en vigencia en todo el territorio aduanero del MERCOSUR y se alcance la aplicación plena en dicho territorio.

Los proyectistas del Código sostienen que entre las fuentes internacionales consideradas para su elaboración figuran instrumentos de la Organización Mundial de Aduanas - el Convenio de Kyoto Revisado (Convención Internacional para la Simplificación y Armonización de los Procedimientos Aduaneros, de 1999) y el Marco Normativo SAFE para asegurar y facilitar el comercio Global (2005) - el Código Aduanero Comunitario Europeo (Reglamento CEE No. 2913/92, 200 artículos) y el Código Aduanero Europeo denominado "Modernizado" (Reglamento CE No 450/2008); el Código Aduanero Uniforme Centroamericano (CAUCA III, 2002, 110 artículos), además del GATT de 1994, y el proyecto de Código Aduanero Andino (256 artículos). (Ríos, 2013).

Se citaron también como fuentes nacionales: el Código Aduanero Argentino (Ley No. 22.415, 1.191 artículos), Código Aduanero Paraguayo (Ley No. 2422/04, 398 artículos, y su Reglamento Decreto No. 4672/05, 391 artículos), Código Aduanero Uruguayo (Decreto Ley No. 15.691/84, 143 artículos), Reglamento Aduanero Brasileño (Decreto No. 4543/2002, 732 artículos y Decreto No. 6.759/o9, originalmente con 810 artículos). (Ríos, 2013).

La estructura del CAM abarca catorce Títulos, 52 Capítulos y 181 artículos que comprenden los siguientes temas:

- Título I - Disposiciones Preliminares y Definiciones Básicas 


\section{CIENCIAS SOCIALES}

- Título II - Sujetos Aduaneros

- Título III - Ingreso de la Mercadería al Territorio Aduanero

- Título IV - Destinos Aduaneros de Importación

- Título V - Egreso de la Mercadería del Territorio Aduanero

- Título VI - Destino Aduanero de Exportación

- Título VII - Tránsito Aduanero

- Título VIII - Regímenes Aduaneros Especiales

- Título IX - Áreas Con Tratamientos Aduaneros Especiales

- Título X - Disposiciones Comunes a la Importación y a la Exportación

- Título XI - Tributos Aduaneros

- Título XII - Derechos del Administrado

- Título XIII - Disposiciones Transitorias

- Título XIV - Disposiciones Finales

Para su aplicación las disposiciones del CAM se ordenan de la forma siguiente: (1) Título; (2) Capítulo; (3) Sección; (4) Artículo; (5) Numeral e (6) Inciso.

No se puede eludir el hecho que en el MERCOSUR se ha dispuesto además dictar normas reglamentarias y complementarias del CAM, las cuales deberán ser aprobadas mediante los instrumentos emitidos por los órganos correspondientes, lo cual podría conducir a una dispersión e inflación normativa en la materia.

Asimismo, la legislación aduanera común no estaría en un único texto refundido, sino que estaría conformada por el CAM y por todas las normas reglamentarias y complementarias que se dicten, siendo aplicables en la totalidad del territorio de los Estados Partes y en los enclaves concedidos a su favor, regulando también el tráfico internacional de los Estados Partes del MERCOSUR con terceros países o bloques de países, pero no se aplicará a los exclaves concedidos en favor de éstos.

El CAM dispone además la supletoriedad de las legislaciones aduaneras de cada Estado Parte dentro de sus respectivas jurisdicciones en aquellos aspectos no regulados 
específicamente por el Código, sus normas reglamentarias y complementarias, manteniendo su validez las normas dictadas en el ámbito del MERCOSUR en materia aduanera - en cuanto no se opongan a las disposiciones del primero - así como los tratados internacionales que se encuentren vigentes en cada Estado Parte a la fecha de entrada en vigor del Código.

Una vez que cada Estado Parte internalice la normativa aduanera común del bloque, deberá aplicarse preferentemente a la normativa nacional, la cual solo tendrá un carácter supletorio, es decir, que cuando haya una colisión de normativa se desaplica la legislación nacional. Los exportadores venezolanos deben solicitar a sus compradores de los otros Estados Partes, información de cualquier intento de aplicación de legislación nacional del Estado importador, a objeto de verificar que no se trate de prácticas discriminatorias o proteccionistas.En el sentido de lo expresado se debe tomar en cuenta que en Venezuela, la Ley Orgánica de Aduanas (LOA), cuya última modificación es de noviembre de 2014 con una "vacatio legis" de 6o días, contiene 194 artículos. El Reglamento de la LOA que se aplica como reglamento general, data de 1978, contenía originalmente 525 artículos, habiendo sido modificado un solo artículo en 1991, el cual se mantiene actualmente.

El articulado del mencionado Reglamento LOA correspondiente a los regímenes aduaneros especiales (extraordinarios), fue derogado en 1996 con la publicación del Reglamento de la LOA sobre los regímenes de liberación, suspensión y otros regímenes aduaneros especiales, contentivo de 152 artículos. Asimismo, el vigente Reglamento parcial de la LOA relativo al Sistema Aduanero Automatizado, del año 2004, consta de 83 artículos y diecisiete disposiciones transitorias y finales. También se encuentra vigente aun cuando no se aplica, el Reglamento Parcial de la LOA Sobre el Régimen Aduanero suspensivo para el Sector Automotor, con quince artículos, el cual sería interesante analizar, a la luz de la política automotriz del MERCOSUR.

En cuanto al Título VI de la LOA correspondiente al contrabando, fue derogado con la promulgación de una ley especial, Ley sobre el Delito de Contrabando. No obstante, debe tenerse en cuenta que la última modificación de la LOA (2008), volvió a publicar íntegramente como parte de la misma, el Título del Contrabando, pero en la última modificación del 2014 lo elimina nuevamente.

La internalización del CAM en el ordenamiento jurídico nacional debe ser un ejercicio de transparencia, toda vez que Venezuela aún no ha publicado en Gaceta Oficial normas del MERCOSUR que el Ejecutivo Nacional debió promulgar teniendo en cuenta lo dispuesto en la Decisión CMC 66/12, aunado a la carencia de una Sección Nacional del Grupo de Mercado Común, lo cual crea riesgos para los operadores económicos, inherentes a la aplicabilidad de una normativa que no ha cumplido con las disposiciones necesarias para su ejecución. 
La adopción y puesta en vigencia del CAM debe ser bien revisada, toda vez que estarán en juego normas reglamentarias y complementarias a ser dictadas por el CMC, el GMC y posiblemente la CCM, así como el hecho cierto que las disposiciones de la legislación aduanera nacional que colidan con las normas del MERCOSUR, deben ser desaplicadas. Lo fundamental del proceso de integración se concreta en la práctica, en la declaración de despacho aduanero y en el reconocimiento de las mercancías, será necesario adecuar la legislación aduanera venezolana, a la normativa aduanera común del bloque, así como evitar la dispersión reglamentaria, mediante la elaboración de un reglamento refundido.

Cabe destacar en virtud de las consideraciones anteriores que Venezuela no asistió a estas reuniones y, por ende, no pudo aportar sus ideas, experiencias y críticas, pese a pertenecer ya a ese bloque de integración. Es necesario resaltar que la aplicación del Arancel Externo Común, las normas de valoración aduanera, las normas de origen y cualesquiera otras normas comunitarias, sólo se perfeccionan en el territorio aduanero establecido en el Código Aduanero del Mercosur, de donde deviene su importancia fundamental.

Otro aspecto resaltante en materia tributaria se destaca: "En materia tributaria también hay cuestiones que merecen ser revisadas en futuros proyectos. Se ha establecido una única obligación tributaria aduanera en sustitución de los derechos de importación y de exportación, y los demás gravámenes hoy vigentes en los Estados Miembros. Por ejemplo, no existe la menor referencia a los derechos antidumping y compensatorios. Tampoco es clara la definición del hecho imponible, puesto que se grava la entrada y salida del territorio aduanero, lo que implica que tanto las destinaciones definitivas como las suspensivas pueden estar alcanzadas con derechos aduaneros. También resulta novedosa la definición del sujeto pasivo. No se considera a la persona que realiza el hecho gravado, sino que se considera responsable al remitente, consignatario o quien tuviere la disponibilidad jurídica de la mercadería". (Cotter, 2010, p.67)

\section{Conclusiones}

El código aduanero MERCOSUR, a pesar de sus contratiempos, considera esta autora que es importante que la Administración Aduanera tome conciencias sobre estos temas y defina bien sus políticas y perspectivas a seguir. Con la modificación de la Ley Orgánica de Aduanas se planteaba la interrogante de si ese era el camino a tomar o el del Código Orgánico Aduanero: nada de esto tendría relevancia. Lo correcto es ver cómo puede afectar este Código Aduanero MERCOSUR a Venezuela e incorporarse a las discusiones del mismo, más ahora que Venezuela pasa a ser un miembro pleno de este acuerdo. 
Cabe mencionar que la remisión a las normas reglamentarias a dictarse debe ser vista como un mandato en favor del desarrollo evolutivo del derecho comunitario aduanero. El CAM armoniza las definiciones, los institutos fundamentales y la estructura del sistema aduanero y, además de ello, indica a quienes deben continuar con la tarea, qué aspectos deberán reglamentar, lo que tendría como efecto una mayor integración y favorecimiento del Bloque Aduanero.

\section{Lista de referencias}

ADAU. (2017). Análisis del código aduanero MERCOSUR y el proyecto de nuevo código aduanero uruguayo. Recuperado de http://www.adau.com.uy/

Ayeran, S., \& Echegaray, R. (2010). Jornada "El Código Aduanero del MERCOSUR desde la óptica de sus redactores" llevada a cabo los días 6 y 7 de setiembre en la Administración de Ingresos Públicos (AFIP) en la ciudad de Buenos Aires Argentina.

Carrazana G, J., (2015). El “código” Aduanero del MERCOSUR. Ámbito Jurídico (LEGIS).

Cotter, J., P. (2010). El Código Aduanero del MERCOSUR, Aprobado por Decisión $\mathrm{N}^{\circ}$ 27/2010 del Consejo del Mercado Común. Instituto Colombiano de Derecho Tributario. Revista 63. ISSN 0122-0799.

Osorio, M. A. (2006). Nuevos Procesos de Integración: Código Aduanero Mercosur. Informe técnico de aduanas.

Ley Orgánica de Aduanas. (2014). Gaceta Oficial de la República Bolivariana de Venezuela número 6.155, Extraordinario de fecha 13 de noviembre de 2014.

Ríos, F. (2013). MERCOSUR: Implicaciones aduaneras para Venezuela (III). Recuperado en: http://www.reportero24.com/2013/o7/21/ mercosur-implicaciones-aduaneras-para-venezuela/

Sacerdote, A., Goldsztein, F., Conde, T., Juárez, H., H. (2013). El Código Aduanero del Mercosur (CAM) - Desde la óptica de sus redactores nacionales. Argentina: Fundación ICBC. 